\title{
Adoção de cursos a distância na Universidade Tecnológica Federal do Paraná: os desafios para os gestores, docentes, técnico-administrativos e discentes
}

\author{
Adoption of distance courses in Federal and Technological \\ University of Paraná: challenges for administrators, teachers, \\ students and administrative technician
}

\author{
Maria Lucia Figueiredo Gomes de Meza ${ }^{52}$ \\ Antonio Gonçalves de Oliveira \\ Ivan Carlos Vicentin \\ Hilda Alberton de Carvalho
}

Artigo recebido em para publicação em out/2012 e aceito para publicação em nov/2012.

\section{Resumo}

O Uso das tecnologias da informação e comunicação (TIC's) são elementos comuns da sociedade contemporânea, sendo freqüentemente usadas nas formas de comunicação, no trabalho e como instrumento de aprendizagem nas organizações e nas escolas. No entanto, apesar da rapidez com que informações e conhecimentos são produzidos e transmitidos na web, a velocidade com que os docentes e discentes são capazes de realizar tais atividades, nas instituições de ensino, são díspares. O problema central que

\footnotetext{
${ }^{52}$ Maria Lucia Figueiredo Gomes de Meza é Doutora em Desenvolvimento Econômico pela UFPR. Professora do Mestrado Profissional em Planejamento e Governança Pública da UTFPR. Pesquisa nas seguintes áreas de interesse: empreendedorismo público, políticas públicas e geração de micros e pequenas empresas e políticas ambientais. Av. Sete de Setembro, 3165. Rebouças CEP 80230-901. Curitiba - PR - Brasil. E-mail: malumeza@utfpr.edu.br Tel.3310-4877.
}

Antonio Gonçalves de Oliveira possui doutorado em Engenharia de Produção pela Universidade Federal de Santa Catarina - UFSC. Atualmente é Professor Adjunto da Universidade Tecnológica Federal do Paraná (UTFPR)/ Departamento Acadêmico de Gestão e Economia (DAGEE) vinculado à Graduação e à Pós-Graduação - Programa de Mestrado em Planejamento e Governança Pública (PPGPGP).E-mail: prof.antoniooliveira@terra.com.br

Ivan Carlos Vicentin é Doutor em Administração pela Universidade de São Paulo. É professor adjunto do departamento de Gestão e Economia da UTFPR, atua como professor de graduação (áreas de Comunicação, Sistemas de Informação). Professor do Mestrado em Planejamento e Governança Pública. E-mail: ivanv@terra.com.br

Hilda Alberton de Carvalho é doutoranda em Tecnologia pela Universidade Tecnológica Federal do Paraná. Atualmente é professora efetiva da Universidade Tecnológica Federal do Paraná. E-mail: hildaalberton@gmail.com 
se coloca neste trabalho é como uma universidade pública pode, dados os limites impostos pelo Estado, inovar na sua forma de gestão e na sua oferta de serviços e/ou produtos à sociedade? O objetivo da pesquisa é analisar a capacidade de inovação da universidade pública, dados os limites impostos pelo Estado. Para tanto, discute-se, teoricamente, as possibilidades de inovação nas universidades públicas (MEZA, 2011; CÁCERES SALA, 2000) a partir da mundialização e das reformas da educação superior (TRINDADE, 2007; CARNOY, 1999; 2004). Metodologicamente é uma pesquisa exploratória e descritiva, baseada no estudo de caso único da UTFPR. Como instrumentos de pesquisa foram utilizados a pesquisa documental, observação participante e entrevistas. Os resultados mostram que a UTFPR ao longo de sua história foi capaz de mudar, quer na sua estrutura organizacional, quer nos seus processos internos, quer em seus métodos pedagógicos, quer seja na oferta de serviços à comunidade regional, como a oferta dos cursos de ensino à distância e com isto novos desafios são colocados aos gestores, docentes, discentes e técnicoadministrativos. Este trabalho contribui para o debate acadêmico porque apresenta as especificidades dos processos de inovação em organização de conhecimento intensivo em serviços.

Palavras-chave: inovação. Organizações de serviços. Universidade pública. Ensino à distância.

\section{Abstract}

The use of information and communication technologies (ICTS) are common elements of contemporary society and is often used forms of communication, at work and as a tool for learning in organizations and schools. However, despite the speed with which information and knowledge are produced and transmitted on the web, the speed with which the teachers and students are able to conduct such activities in educational institutions is mixed. The central problem that arises in this paper is how a public university can, given the limitations imposed by the state, innovate in its management and in its provision of services and / or products to the company? The objective of the research is to analyze the innovation capability of the public university, given the limits imposed by the state. So, we discuss theoretically the possibilities for innovation in public universities (MEZA, 2011; CÁCERES ROOM, 2000) from the globalization and reforms of higher education (TRINITY, 2007, Carnoy, 1999, 2004). Methodologically is an exploratory and descriptive, based on a single case study of UTFPR. The research tools were used to document research, participant observation and interviews. The results show that UTFPR throughout its history has been able to change, both in its organizational structure, both in its internal processes, both in their teaching methods, whether in providing services to the regional community, such as the provision of distance learning courses and with it new challenges are posed to managers, teachers, students and technical administrators. This paper contributes to the academic debate 
because it presents the specificities of innovation processes in the organization of knowledge-intensive services

Keywords: innovation. Service organizations. Public university. Distance learning.

\section{Introdução}

As tecnologias da informação e comunicação (TIC's) são elementos comuns da sociedade contemporânea e, com elas, novas formas de se comunicar, trabalhar e aprender foram desenvolvidas. No entanto, apesar da rapidez com que informações e conhecimentos são produzidos e transmitidos na web, a velocidade com que os docentes e discentes são capazes de realizar tais atividades, nas instituições de ensino, são díspares. Diante destas considerações, as questões que se colocam neste trabalho são: Por que ainda há muitos docentes no nosso País incrédulos à realização de um ensino à distância com qualidade? Por outro lado, como motivar a aprendizagem dos discentes, habituados a se comunicar pela internet, por meio das tecnologias da informação respeitando os processos inerentes de reflexão para o desenvolvimento do conhecimento? Se, por um lado, os professores desacreditam na capacidade de ensinar com qualidade à distância; por outro lado, os alunos acreditam que o acesso por si só a uma ampla quantidade de informações e conceitos é o suficiente para terem os conhecimentos necessários à sua formação, denominados aqui pela autora de pseudo segurança do saber. Isto significa dizer que os alunos universitários crêem que, por terem acesso rapidamente e facilmente, a gabaritos de exercícios, por exemplo, consideram o contato com os professores desnecessários, pois com tal material já adquiriram 0 conhecimento, o que é uma falsa segurança do saber. Tal fato é comum ocorrer com os programas de monitoria, na graduação, por exemplo. E, neste caso, consideramos tais questões também para os cursos presenciais e semi-presenciais, que igualmente utilizam recursos on line para planejar, executar e avaliar parte das atividades de ensino e de pesquisa. Diante disto, será que estamos formando profissionais adequados aos desafios impostos pelo mercado de trabalho? Por outro lado, a oferta de cursos na modalidade à distância coloca novos desafios à gestão tradicional e burocrática da universidade pública. E, neste caso, Como motivar e capacitar técnico-administrativos e docentes para tais mudanças? A partir deste cenário, o objetivo deste trabalho é analisar a capacidade de inovação da universidade pública, dados os limites impostos pelo Estado. O problema que se coloca nesta pesquisa é como uma universidade pública pode, dados os limites impostos pelo Estado, inovar na sua forma de gestão e na sua oferta de serviços e/ou produtos à sociedade? Para responder ao problema colocado, este trabalho está dividido em três partes. Além desta introdução, na segunda parte, exploram-se o debate sobre novas formas de se inovar na gestão e na oferta de serviços e/ou produtos no âmbito das universidades públicas 
(MEZA, 2011; CÁCERES SALA, 2000) a partir da mundialização e das reformas da educação superior (TRINDADE, 2007; CARNOY, 1999; 2004); E, na terceira parte, faz-se uma análise descritiva da implantação de novos mecanismos de gestão e de novos cursos de especialização à distância na Universidade Tecnológica Federal do Paraná - UTFPR, antigo Centro Federal de Educação Tecnológica do Paraná (Cefet-PR); destacando os desafios para gestores, docentes, técnico-administrativos e discentes.

Em relação aos aspectos metodológicos, no que concerne à finalidade da pesquisa, este trabalho é exploratório e descritivo, pois se exploram o debate sobre novas formas de se inovar na gestão e na oferta de serviços e/ou produtos no âmbito das universidades públicas a partir da mundialização e das reformas da educação superior; utilizando-se como instrumentos de investigação a pesquisa bibliográfica. $E$, também é descritivo porque se faz uma análise descritiva da implantação de novos mecanismos de gestão e de novos cursos de especialização à distância na Universidade Tecnológica Federal do Paraná - UTFPR, antigo Centro Federal de Educação Tecnológica do Paraná (Cefet-PR); destacando os desafios para gestores, docentes, técnico-administrativos e discentes. Nesta etapa da pesquisa, os instrumentos utilizados no estudo de caso foram: pesquisa a fontes documentais, observações participantes e entrevistas com gestores e docentes.

\section{Novas Formas de se Inovar na Gestão e na Oferta de serviços e/ou produtos nas Universidades Públicas Brasileiras}

Neste capítulo discutiremos as reformas universitárias, que ocorreram no Brasil, a partir de 1930, para compreender a natureza das universidades públicas. O texto apresenta duas grandes reformas instituídas entre o período de 1930-70, que definiram o marco regulatório do ensino no País, modificando o ambiente universitário no que se refere ao seu aparato jurídico-normativo, a suas estruturas e seus processos internos. Estas reformas instituíram o estatuto das universidades públicas (Reforma de 1930) e a expansão e privatização do ensino no País (Reforma de 1968). E, recentemente, durante o governo Lula em 2004, a reforma universitária se tornou prioridade na agenda do governo, cujas propostas visam diversificar as fontes de financiamento da educação superior pública e a alocar verbas públicas para as universidades privadas a fim expandir o ensino superior no País, tornando-o mais democrático. Estas orientações compartilham das propostas dos organismos internacionais, que sugerem menor participação do Estado com gastos na educação e a unificação de um modelo de ensino superior, que privilegie o "saber profissional". Estes fatos afetam o papel e as ações das universidades públicas e delimitam suas possibilidades de inovações, que também é discutida, neste capítulo, a partir do debate teórico sobre os tipos de inovações em instituições de serviços. Ademais, 
este debate é feito buscando visualizar as possibilidades de inovações nas universidades públicas.

\section{O Perfil das Universidades Públicas Brasileiras}

Para analisar o perfil das universidades públicas brasileiras partimos da discussão sobre a reforma universitária no Brasil, pois historicamente, ela reflete a própria natureza das universidades públicas. Segundo Trindade (2007, p.32), "o conceito de reforma universitária permaneceu, até hoje, na memória política como uma referência simbólica de uma concepção de universidade com missão acadêmica, compromisso social e gestão democrática". Ainda este autor afirma que tais reformas se caracterizaram, fundamentalmente, por mudanças, nos mecanismos de eficiência por meio de novos sistemas de avaliação e pressões por relações mais estreitas com o setor produtivo.

No Brasil, o modelo de universidade pública decorreu, salvo nos casos da Universidade de São Paulo (USP) e da Universidade do Distrito Federal (UDF) ${ }^{53}$, a partir da Revolução de 1930 como um projeto estatal, que repete as mesmas características de um Estado-desenvolvimentista. Este modelo estatal foi implantado através da criação de agências e empresas estatais. Ele se caracteriza por ser o Estado que legisla sobre elementos fundamentais, tais como, estrutura funcional (departamental), democracia interna (órgãos decisórios) e a forma de produção e reprodução do conhecimento (unidade entre ensino e pesquisa).

Desde a década de 1930 até os dias atuais, podemos caracterizar o processo de mudanças no ensino superior como uma luta entre privatismo liberal-positivista, característico do período anterior à República no Brasil; e nacional-autoritarismo, da Revolução de 1930. Desde essa década, duas reformas universitárias ocorreram: a reforma de 1931, no governo Provisório de Vargas, que instituiu o estatuto das universidades brasileiras; e a de 1968, em plena ditadura militar, que possibilitou inserir a iniciativa privada na educação superior, com o papel complementar aos das instituições públicas para atender à crescente demanda. Ambas foram gestadas sob o poder de regimes autoritários e registraram momentos em que se constituíram duas leis gerais sobre educação superior, que tiveram uma longa vigência: uma em 1931 e a outra em 1968, sendo esta vigente até hoje no País. Posteriormente, a constituição Federal de 1988 também estabeleceu algumas orientações gerais sobre a educação, mas partindo das propostas da última reforma.

A partir de tais reformas, a universidade pública é definida no Brasil como uma instituição que deve reunir, pelo menos, três das seguintes

\footnotetext{
${ }^{53}$ Estas universidades se instituíram não sob a cátedra imposta pelo governo federal brasileiro, mas ao molde mais descentralizado e democrático de gestão dos modelos de universidades norte-americanos. Para mais detalhes ver Trindade (2007).
} 
unidades: Direito, Medicina, Engenharia e Educação, Ciências e Letras, sem referência à Filosofia. Deve ainda dispor de "capacidade didática" (professores, laboratórios etc.) e "recursos financeiros concedidos pelos governos: federal (universidades federais) e estadual (universidades estaduais). Seus estatutos devem ser aprovados pelo Ministro da Educação e Saúde Publica e "só poderão ser modificados por proposta do Conselho Universitário ao Ministro, ouvido o Conselho Nacional de Educação (CNE) (Art. 7) ${ }^{54}$. Em relação ao processo decisório, ela é administrada por um Reitor e por um Conselho Universitário (incluindo a Secretaria Geral e a Contabilidade etc.). Pode-se ter também a Assembléia Universitária, que é constituída pelo conjunto dos professores de todos os Institutos Universitários. Este, por sua vez, é composto, administrativamente, por Diretor; do Conselho Técnico Administrativo e da Congregação. E a carreira docente se classifica por: professores catedráticos, auxiliares de ensino, docentes livres e, eventualmente, professores contratados. É uma instituição pública, que é regida pela lei federal, pelo seu estatuto de criação, pelo Regimento Geral, pelos regulamentos e resoluções internas; e possui autonomia didático-científica, disciplinar, administrativa, de gestão financeira e patrimonial.

No que se refere à autonomia didática, a instituição pode oferecer cursos, organizar eventos, dentre outras atividades educacionais, que "destinam-se, principalmente, à difusão de conhecimento útil à vida social e coletiva, à solução de problemas sociais e à propagação de idéias e princípios que salvaguardem os altos interesses nacionais" (Art. 42; parágrafo único).

$\mathrm{E}$, a mais recente reforma universitária que se pretende realizar no País, começou a ser implantada, desde 2004, já no segundo mandato do governo federal Lula, quando ela foi trazida para a agenda de prioridades do governo, depois de várias décadas ${ }^{55}$.

No âmbito do governo foi elaborado um documento pelo Grupo de Trabalho (GT) interministerial ${ }^{56}$ intitulado Bases para o enfrentamento da Crise Emergencial das Universidades Federais e Roteiro para a Reforma Universitária Brasileira. O foco central deste documento é a defesa da diversificação das fontes de financiamento da educação superior pública e a alocação de verbas públicas para as universidades privadas - Pacto de Educação pelo Desenvolvimento Inclusivo e o recém lançado Programa Universidade Para Todos (ProUNI) - (MEC, 2004). Este projeto tem a

\footnotetext{
${ }^{54}$ Este artigo e os demais apresentados nos próximos parágrafos foram extraídos do Decreto № 19.851, de 11/04/1931 (ver: Senado Federal/ Subsecretaria de Informações em: www.senado.gov.br).

${ }^{55}$ Entre a CF de 1988 até o governo Lula várias regulamentações (as várias versões da Lei de Diretrizes e Bases- $L D B$ ) foram publicadas para orientar a educação no País.

${ }^{56}$ Este Grupo de Trabalho foi composto por representação da Casa Civil, da Secretaria Geral da Presidência da República, do Ministério da Educação, do Ministério do Planejamento, do Ministério da Fazenda e do Ministério da Ciência e Tecnologia (Brasil, GT Interministerial, 2003).
} 
finalidade de garantir às pessoas carentes o ensino superior, por meio de bolsas de estudos em instituições privadas, que são financiadas pelo governo federal. Para alguns pesquisadores, a lógica aqui é similar ao que ocorreu entre as décadas de 1980-90, quando o governo incentivou financeiramente, empresários na educação privada por meio de isenção fiscal. E, neste contexto, a educação à distância também tem representado uma estratégia de governo para democratizar o acesso à educação superior, em um cenário de mercados mundializados e de valorização do conhecimento.

Já para Trindade (2007) o principal avanço que a reforma tem instituído no governo Lula foi a iniciativa da Secretaria da Educação Superior, do Ministério da Educação/SESu, em meados de 2003, de criar uma Comissão Especial de Avaliação, que elaborou a proposta de um novo Sistema Nacional de Avaliação Institucional (SINAES), aprovado pelo Congresso através da Lei no 10.861 de 14 de abril de 2004 e, atualmente, em fase de implantação sob a responsabilidade de uma recém-criada Comissão Nacional de Avaliação da Educação Superior.

Tais mudanças resultaram de debates públicos democráticos através de "audiências públicas regionais", que promovem debates com entidades representativas dos reitores, segmentos da comunidade acadêmica e setores mais amplos da sociedade. A proposta é que seus resultados sejam articulados com as políticas do MEC para a criação de um projeto de uma nova reforma universitária. É uma ousadia promover tais mudanças já que as leis universitárias anteriores foram elaboradas em situações autoritárias e, por outro lado, há desafio de alto risco político diante das tendências restritivas da economia brasileira para ampliar os níveis de financiamento público, as resistências tradicionais às mudanças das instituições públicas e a capacidade de pressão sobre o Congresso do setor privado.

Ainda para Trindade (2007, p.48) os desafios de uma reforma universitária no Brasil são enormes e complexos, pois

"a nova reforma deve ser capaz de responder questões
emblemáticas, como: 1) qual o papel do Estado, no contexto da
economia mundializada, para enfrentar a reforma de um sistema
de público/privado tão desequilibrado? 2) Qual o nível de
massificação aceitável para o sistema público de educação
superior para que ele possa cumprir suas funções inovadoras na
pesquisa fundamental e aplicada para as novas economias? 3)
Qual a função estratégica da universidade na construção de um
projeto de Nação soberana e inserida na competição
internacional na geração de conhecimentos científicos e
tecnológicos?"

Ademais, ele aponta as orientações diversas com que o País se direciona e as propostas de organismos internacionais, que sugerem, baseados nos conceitos de "sociedade do conhecimento mundializada" e da educação como "bem público global", o rompimento com qualquer projeto de inserção nacional soberana no processo. O bem público perde sua referência republicana e nacional para diluir-se na confluência entre a governança e as estratégias de expansão dos provedores educacionais transnacionais. 
Segundo Carnoy (1999), a idéia aqui mostra as conseqüências da mundialização sobre os sistemas educacionais. O mercado de trabalho demanda uma mão-de-obra com maior conhecimento tecnológico, por um lado, e a necessidade de créditos suplementares para educação num contexto de uma conjuntura hostil a expansão do setor público, por outro lado. Se o saber é essencial à mundialização, esta deve ter influência sobre a transmissão do conhecimento realizado nas instituições de ensino. E, como o capital financeiro internacional tem interesses econômicos de curto prazo, tal perfil favorece as instituições de ensino privadas, que não tem sua gestão a burocracia estatal, que se torna um obstáculo para inovações mais rápidas nos produtos, serviços, processos; e nos métodos de gestão e de divulgação.

Então, a partir do processo de mundialização e o seu impacto sobre as estratégias da reforma da educação, que devem se orientar pelos pressupostos de competitividade (OECD; UNESCO) e pelos imperativos financeiros (impostos pelo FMI), a proposta é que se diminuam as despesas públicas com a educação, principalmente com o ensino médio e superior, e estimulem a iniciativa privada para estas atividades. Carnoy (1999, p.17) ainda conclui que "o projeto mais amplo de restrição à despesa pública no campo da educação corre o risco de impedir os Estados de escolher os meios mais eficazes de desenvolver e melhorar o ensino no contexto da nova economia mundial".

A partir da segunda metade do século $X X$, em toda a América Latina, inclusive no Brasil, o ensino superior se tornou mais massificado e privatizado. A massificação ocorreu mediante o maior número de matrículas no ensino superior de jovens de 18 a 24 anos, sendo o período entre 198090 o de maior crescimento. No Brasil este crescimento foi da ordem de $11 \%$ no período, mas inferior a outros países latino americanos, que cresceram acima de 20\% (Argentina, Equador, Costa Rica e Venezuela) e entre 20 a $15 \%$ (Peru, Uruguai e Chile) - (TRINDADE, 2007, p.56). No tocante à privatização, a partir deste período, o número de criação de universidades privadas é quatro vezes superior aos das públicas na América Latina. No Brasil, este crescimento foi ainda maior, o que o tornou o sétimo país num ranking mundial onde os Estado Unidos é o vigésimo (CARNOY, 2004).

\section{Possibilidades de Inovação nas Universidades Públicas: o caso da UTFPR}

As possibilidades de inovação são entendidas a partir do conceito de inovação, publicado no Manual de Oslo (1997), que se fundamenta teoricamente no modelo de inovação interativa (KLEIN; ROSENBERG, 1986). Este modelo não tem uma visão linear do processo inovativo e se baseia nas especificidades das empresas de serviços, que são muito diferentes das indústrias e demandam novos estudos sobre a discussão de inovações tecnológicas (GALLOUJ, 2007). Neste caso, entendemos inovação como a capacidade da organização de colocar no mercado novos produtos e/ou serviços (na perspectiva schumpeteriana) ou realizar 
melhorias nos seus produtos e/ou serviços, como também nos seus processos operacionais, nos métodos de gestão e de marketing. Podemos então sintetizar quatro tipos de possibilidades de inovação nas empresas de serviços, a saber: (GALLOUJ, idem): inovação do produto-serviço, de processo, organizacional e de relação externa. A universidade pública como uma instituição de serviços pode realizar todas estas possibilidades de inovação.

A inovação produto-serviço nas empresas de serviços considera ao mesmo tempo produtos materiais e imateriais, como novos métodos de treinamento, novas áreas de consultoria, etc. No caso da universidade pública, a oferta de novos produtos tecnológicos (produtos materiais) pode se dá a partir dos projetos de pesquisa de professores e/ou alunos, dos cursos de graduação e de pós-graduação, que resultam em artefatos sóciotécnicos, principalmente nas áreas das engenharias, medicina e biologia; e os patenteiam para a comercialização; sendo que os processos de inovação podem ser desenvolvidos de forma independente pela universidade e/ou em parceria com outras instituições de pesquisa pública ou privadas. A UTFPR tem vários produtos patenteados em decorrência de seu perfil histórico voltado para o ensino e a prática, sendo muitas dessas inovações realizadas em conjunto com empresas locais. Um caso de sucesso foi o projeto desenvolvido, no âmbito do mestrado em Engenharia Elétrica e de Sistemas de Informação. Um aluno de cada curso deste, em parceria, desenvolveram uma miniimpressora para emissão de notas fiscais, que contribui na automação bancária e comercial; e hoje a empresa é reconhecida no mercado ${ }^{57}$.

No que se refere a novos serviços, podemos destacar a oferta de novos cursos de graduação de curta duração e mais voltados para a prática do mercado, como os tecnólogos; como também a oferta de novos cursos técnicos, de graduação e pós-graduação à distância ou semipresencial. No caso da UTFPR, apenas o curso de graduação ainda não é oferecido nesta modalidade.

A inovação do processo, por sua vez, abrange sistemas técnicos ou de processos mais imateriais, como o método dos consultores. No caso das universidades públicas, os métodos de ensino são continuamente repensados, como também a inserção das tecnologias de informação e comunicação (TIC's) modifica os processos didáticos e administrativos. Como exemplos, podemos citar o caso da informatização do processo de avaliação dos servidores públicos, programação de férias on line, realização de matrícula pelo aluno num sistema informatizado e treinamento de servidores à distância, como administrativos; já no tocante aos processos pedagógicos, incluímos aqui as ferramentas de informática, que possibilitam o aluno acessar o material de aula, acompanhar recentes publicações de seus professores, participarem de fóruns virtuais dentre outros; que ocorreram no âmbito da UTFPR.

\footnotetext{
${ }^{57}$ Ver: http://www.bematech.com.br
} 
A inovação organizacional (interna) constitui a estrutura de atendimento das atividades e dos processos. Nas universidades públicas, essas mudanças podem ocorrer ao se modificar ou melhorar as estruturas organizacionais. As mudanças nas formas de gestão, passando a ser mais descentralizada e compartilhada entre o Reitor e o Conselho Universitário, que é um órgão de representatividade da comunidade universitária são exemplos de mudanças na estrutura e compartilhamento de poder na organização.

E, a inovação de relação externa é definida como a implantação de relações particulares com os parceiros da organização, sejam eles clientes, fornecedores, instituições públicas ou concorrentes. O que talvez menos se realize nas universidades públicas seja as inovações deste tipo quando se trata de relações concorrenciais, pois, como instituições públicas e gratuitas, a concorrência pela procura de vagas é elevada, desestimulando as inovações nas formas de divulgação de seus cursos; salvo nos de especialização, que podem ser cobrados taxas por meio das fundações e, neste caso, a divulgação é mais dinâmica. No caso da UTFPR, a instituição é muito ativa com a relação com a comunidade. Ela possui uma diretoria de Relações Empresariais e Comunitárias (DIREC-CT), que tem como missão "promover a interação entre universidade-empresa-comunidade, por meio da gestão dos processos de extensão, visando o desenvolvimento sociotecnoeconômico regional sustentável" (UTFPR, 2012). Esta diretoria apóia atividades de desenvolvimento tecnológico; estágios, empregos, qualificação profissional e apoio aos egressos; e atividades de extensão e relações interempresariais. Desde 2005, mensalmente é publicado um boletim informando todas as ações promovidas por esta diretoria.

\section{Implantação de Novos Mecanismos de Gestão e de Novos Cursos de Especialização à Distância na Universidade Tecnológica do Paraná - UTFPR}

Neste capítulo partimos da história da UTFPR, que é o nosso estudo de caso. A recente transformação da instituição em universidade gerou inúmeras mudanças nos processos internos para se adequar ao novo perfil institucional; ao mesmo tempo em que os aspectos culturais herdados desde a sua criação, em 1910, como Escola de Aprendizes Artífices; foram mantidos e/ou adaptados a sua nova realidade. E, um traço marcante de sua cultura, dada sua vocação para a formação de engenheiros, é o desenvolvimento do ensino em conjunto com a prática, sendo esta realizada nos inúmeros laboratórios técnicos da instituição e a partir da parceria com empresas locais. $E$, desde a sua transformação em universidade, a instituição continua crescendo, principalmente após a adesão, em 2008, ao Programa de Apoio aos Planos de Reestruturação e Expansão e das Universidades Federais (Reuni). Todos estes fatos fortaleceram a UTFPR como instituição e possibilitou acumular experiências e conhecimentos para promover inovações em produtos, serviços, processos, estruturas 
organizacionais e relações com o ambiente externo. Particularmente, analisaremos as inovações de serviços, especificamente a oferta do Curso de Especialização em Gestão Pública Municipal (GPM), que é objeto de análise desta pesquisa. E, neste estudo específico, também são explorados os desafios que criam para os gestores, docentes, discentes e técnicoadministrativos na instituição.

\section{A história da Universidade Tecnológica Federal do Paraná (UTFPR)}

A UTFPR é uma instituição pública, gerida por recursos públicos federais com uma história de pouco mais de cem anos. Ela foi fundada em 1909, como Escola de Aprendizes Artífices ${ }^{58}$. Nos anos seguintes, a escola cresceu em números de alunos, professores, técnico-administrativos e em instalações decorrentes da expansão da oferta de seus cursos.

No final da década de 1930, o ensino se tornou mais profissional e ela passou a oferecer cursos correspondentes ao ensino médio de hoje ${ }^{59}$.

$\mathrm{Na}$ década de 1940, houve uma organização do ensino industrial no País e a instituição passou a se chamar Escola Técnica de Curitiba. Três anos depois, foram oferecidos os primeiros cursos técnicos, a saber: Construção de Máquinas e Motores, Edificações, Desenho Técnico e Decoração de Interiores.

$\mathrm{Na}$ década posterior, a instituição se beneficiou de um acordo estabelecido entre o Brasil e os EUA na área do ensino industrial, o que possibilitou a formação e o treinamento de seu corpo docente, melhorando, sobremaneira, a qualidade de seus cursos. Mais uma reforma ocorreu no ensino industrial no País, no final da década de 1950, unificando o ensino técnico, que antes eram divididos em ramos. Neste período, a instituição ganhou maior autonomia, passando a chamar-se Escola Técnica Federal do Paraná e a ser considerado como unidade escolar padrão no Estado, principalmente com a configuração do ensino de $2^{\circ}$ grau que, orientado pela lei $n^{0} 5.692 / 71$, dava ênfase especial à formação para o trabalho.

No final da década de 1960, as Escolas Técnicas eram o modelo de sucesso do novo ensino de $2^{\circ}$ grau profissionalizante (hoje equivalente ao ensino médio), com destaque de seus alunos no mercado de trabalho, assim como o ingresso em cursos superiores de qualidade, elevando seu conceito na sociedade. Nesse cenário, a Escola Técnica Federal do Paraná destacava-se pelos seus cursos profissionalizantes, passando a ser referência para esta modalidade no Estado e no País.

\footnotetext{
${ }^{58} \mathrm{O}$ ensino era destinado a meninos de camadas menos favorecidas da sociedade, chamados de "desprovidos da sorte". Pela manhã, esses meninos recebiam conhecimentos elementares (primário) e, à tarde, aprendiam ofícios nas áreas de alfaiataria, sapataria, marcenaria e serralheria. Inicialmente, havia 45 alunos matriculados na escola, que, logo em seguida, instalou seções de Pintura Decorativa e Escultura Ornamental.

${ }^{59} \mathrm{Na}$ época estes cursos eram denominados do Ginásio industrial e a instituição passou a se chamar Liceu Industrial do Paraná.
} 
A partir de 1974, por autorização especial do Ministério da Educação e Cultura (MEC), passou a ministrar Cursos superiores (de curta duração) de Engenharia de Operação, na área de Construção Civil e Elétrica. Quatro anos depois, em 1978, a Instituição foi transformada em Centro Federal de Educação Tecnológica do Paraná (CEFET-PR), passando a ministrar cursos de graduação plena como os de Engenharia Industrial Elétrica, ênfase em Eletrotécnica e Engenharia Industrial Elétrica, ênfase em Eletrônica/Telecomunicações; e Curso Superior de Tecnologia em Construção Civil, posteriormente, em 1986, Engenharia de Produção Civil e, em 1992, Engenharia Industrial Mecânica.

A partir da implantação dos Cursos superiores, deu-se início ao processo de "maioridade" da Instituição, que avançaria, nas décadas de 80 e 90, com a criação dos Programas de Pós-Graduação.

Em 1990, o Programa de Expansão e Melhoria do Ensino Técnico fez com que o CEFET-PR se expandisse para o interior do Paraná, onde implantou a primeira Unidade de Ensino Descentralizada, na cidade de Medianeira, na região oeste do Estado do Paraná. Em 1993, foram implantadas as Unidades de Cornélio Procópio, Pato Branco e Ponta Grossa e, em 1994, foi incorporada à Unidade de Pato Branco a Faculdade de Ciências e Humanidades existente naquela cidade. No ano de 1995, foi implantada a Unidade de Campo Mourão e, em 2003, a Escola Agrotécnica Federal de Dois Vizinhos foi incorporada ao CEFET-PR. Com a Lei de Diretrizes e Bases da Educação (LDBE), de 1996, que não permitia mais a oferta dos Cursos técnicos integrados, a Instituição, tradicional na oferta desses cursos, decidiu implantar o Ensino Médio e os cursos de Tecnologia. A partir de então, houve um redirecionamento das prioridades do CEFETPR para o ensino superior, com expansão também da pós-graduação stricto sensu.

Em outra perspectiva do processo de expansão, a Instituição estrategicamente abriu uma nova frente: os intercâmbios internacionais de docentes e discentes, iniciando com as Fachhochschules $(\mathrm{FH})$ da Alemanha, dada a similaridade com a identidade do CEFET-PR. Em seguida, estendeu-se para instituições francesas, espanholas, japonesas, americanas, dentre outras.

Assim, a trajetória do CEFET-PR pode ser subdividida em três fases principais. A primeira, de 1979 a 1988, responsável, principalmente, pela inserção institucional no contexto das entidades de ensino superior, o que possibilitou a implantação do primeiro Programa de Mestrado. A segunda, de 1989 a 1998, marcada pela expansão geográfica e pela implantação dos Cursos Superiores de Tecnologia. E, a última fase, iniciada em 1999, que vem se caracterizando pela consolidação de um novo patamar educacional, para o qual se promoveram os ajustes necessários para a sua transformação em universidade.

O Projeto de Lei oㅜ 11.184/2005 que transformou o CEFET-PR em Universidade Tecnológica Federal do Paraná foi sancionado pelo Presidente da República, em 2005. A iniciativa de pleitear junto ao Ministério da Educação - MEC a transformação teve origem na comunidade 
interna, pela percepção de que os indicadores acadêmicos nas suas atividades de ensino, pesquisa, extensão e gestão, credenciavam a Instituição a buscar a condição como Universidade Especializada, em conformidade com o disposto no Parágrafo Único do Artigo 53 da Lei de Diretrizes e Bases da Educação - LDBE, Lei no 9.394, de 20 de dezembro de 1996.

No ano de 2007 foi autorizada a implantação dos Câmpus de Apucarana, Londrina, Toledo e, em 2008, o Campus de Francisco Beltrão.

Atualmente, a UTFPR possui 28.657 alunos matriculados, 1.889 docentes, 913 técnico-administrativos, distribuídos em 12 Câmpus no Estado do Paraná: Apucarana, Campo Mourão, Cornélio Procópio, Curitiba, Dois Vizinhos, Londrina, Medianeira, Pato Branco, Ponta Grossa, Toledo, Guarapuava e Francisco Beltrão.

\section{Os Projetos dos Cursos à Distância como modalidades de inovação dos serviços}

A UTFPR começou a oferecer cursos de ensino à distância desde 2007, no Câmpus de Medianeira, com a oferta de cursos de especialização pela $U A B^{60}$. E, em 2009, ela também passou a oferecer cursos técnicos por meio do Sistema Escola Técnica Aberta do Brasil $(E-T e c)^{61}$; além de desenvolver um projeto piloto de curso de extensão voltado aos seus servidores.

As especializações à distância, na modalidade semi-presencial, são resultado de uma parceria entre a UTFPR, a Universidade Aberta do Brasil (UAB), órgão do Ministério da Educação responsável pelo ensino a distância, e as prefeituras das cidades.

Atualmente existem cinco cursos de especialização ofertados em três Câmpus a 16 pólos presenciais, localizados em municípios na região sul e nordeste do País (Quadro 1).

\footnotetext{
${ }^{60}$ O Sistema Universidade Aberta do Brasil (UAB) é um programa criado pelo Ministério da Educação, em 2005, com a prioridade de formar professores para a Educação Básica. Para atingir este objetivo central a UAB realiza ampla articulação entre instituições públicas de ensino superior, estados e municípios brasileiros, para promover, através da metodologia da educação a distância, acesso ao ensino superior para camadas da população que estão excluídas do processo educacional.

${ }^{61}$ Sistema Escola Técnica Aberta do Brasil - e-Tec Brasil foi instituído pelo Decreto № 6.301, de 12 de dezembro de 2007 como uma das ações do Plano de Desenvolvimento da Educação. Seu objetivo primário é: "expandir e democratizar a oferta de cursos técnicos de nível médio, especialmente para o interior do País e para a periferia das áreas metropolitanas". Operacionalmente, se realiza por meio da colaboração entre a União e os Estados, o Distrito Federal e os Municípios, cujas ações devem contemplar: I - cursos técnicos de nível médio, na modalidade de educação a distância, por instituições públicas que ministrem ensino técnico de nível médio, em articulação com estabelecimentos de apoio presencial; e II - formação continuada e em serviço de professores da educação profissional de nível médio, na modalidade de educação a distância.
} 
No caso dos cursos oferecidos por meio do E-Tec, atualmente a instituição tem dois cursos ofertados em cinco Câmpus, para 11 turmas, que contam com dez pólos presenciais e atendem a 420 alunos (Quadro 1).

\begin{tabular}{|c|c|c|c|}
\hline & Campus & Cursos & Pólos \\
\hline \multirow{3}{*}{ 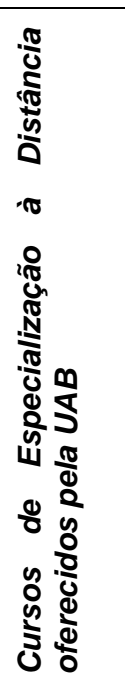 } & Medianeira & $\begin{array}{ll}\text { Gestão Ambiental } & \text { em } \\
\text { Municípios } & \\
\text { Educação: Métodos } & \text { e } \\
\text { Técnicas de Ensino } & \\
\text { Ensino de Ciências } & \end{array}$ & $\begin{array}{l}\text { Foz do Iguaçu (PR) } \\
\text { Mata de São João } \\
\text { (BA) } \\
\text { Paranavaí (PR) } \\
\text { Rio Negro (PR) } \\
\text { Nova Santa Rosa } \\
\text { (PR) } \\
\text { Jaú (SP) } \\
\text { Mirandópolis (SP) } \\
\text { Peruíbe (SP). }\end{array}$ \\
\hline & Pato Branco & Gestão Pública & $\begin{array}{l}\text { Paranavaí (PR) } \\
\text { Osasco (SP) }\end{array}$ \\
\hline & Curitiba & Gestão Pública Municipal & $\begin{array}{l}\text { Telêmaco Borba (PR) } \\
\text { Goioerê (PR) } \\
\text { Itapetininga (SP) } \\
\text { Apiaí (SP) } \\
\text { São José dos } \\
\text { Campos (SP) }\end{array}$ \\
\hline \multirow{5}{*}{ 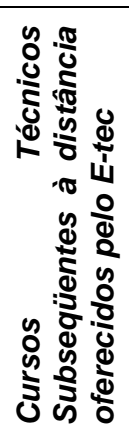 } & $\begin{array}{l}\text { Campo } \\
\text { Mourão }\end{array}$ & $\begin{array}{l}\text { Técnico Subseqüente em } \\
\text { Meio Ambiente }\end{array}$ & Engenheiro Beltrão \\
\hline & Curitiba & $\begin{array}{l}\text { Técnico Subseqüente em } \\
\text { Meio Ambiente }\end{array}$ & $\begin{array}{l}\text { Contenda } \\
\text { Curiúva. }\end{array}$ \\
\hline & Medianeira & $\begin{array}{l}\text { Técnico Subseqüente em } \\
\text { Informática }\end{array}$ & $\begin{array}{l}\text { Foz do Iguaçu e São } \\
\text { Miguel do Iguaçu }\end{array}$ \\
\hline & Pato Branco & $\begin{array}{l}\text { Técnico Subseqüente em } \\
\text { Informática }\end{array}$ & $\begin{array}{l}\text { Entre Rios do Oeste } \\
\text { Sarandi } \\
\text { Uraí. }\end{array}$ \\
\hline & $\begin{array}{l}\text { Ponta } \\
\text { Grossa }\end{array}$ & $\begin{array}{l}\text { Técnico Subseqüente em } \\
\text { Informática para Internet }\end{array}$ & $\begin{array}{l}\text { Balsa Nova } \\
\text { Curiúva } \\
\text { Figueira. }\end{array}$ \\
\hline
\end{tabular}

Quadro 1 - Cursos de Especialização e Técnicos oferecidos pela UTFPR na modalidade à distância por Campus e Pólos Presenciais Fonte: UTFPR (2012)

Nota: Elaborado pelos autores

Quanto ao projeto piloto de extensão à distância, a instituição oferece o curso em Inovação, que deve ser concluído em março, para cerca de 20 servidores dos seus 11 Câmpus. O curso tem seis módulos de 20h/a cada: Propriedade Intelectual - redação de patentes; Propriedade intelectual - busca de anterioridade; Propriedade intelectual documentação; Propriedade intelectual - regulamento de PI da UTFPR; Empreendedorismo - PROEM - disseminação da cultura; e Empreendedorismo - PROEM - mecanismos HT e IUT. 
No ano que vem, será formada uma nova turma, de 10 a 20 alunos de cada campus da UTFPR, com aulas durante o primeiro semestre.

\section{O Caso do Curso de Especialização em Gestão Pública Municipal (GPM)}

O Curso de Especialização em GPM foi implantado em 2010 e hoje possui duas turmas, com 50 alunos cada e 14 professores. É o primeiro curso de especialização à distância implantado no Câmpus de Curitiba e o seu projeto, organização e operacionalização têm trazido inúmeros desafios aos professores, gestores, técnicos administrativos e alunos.

O projeto do curso foi desenvolvido com o apoio do Departamento de Gestão e Economia (DAGEE), tendo a frente o perfil empreendedor de um professor, que é o atual coordenador do Curso. Após a sua concepção, a equipe contou com o apoio sistêmico (tecnologias da informação e comunicação - TIC's) e instrumental (registro de controle acadêmico) do Câmpus de Medianeira, haja vista a gestão descentralizada e devido a sua experiência acumulada por ter sido o Câmpus precursor na oferta dos cursos à distância na instituição. Já a operacionalização do curso é independente, conforme as regras formalizadas no projeto do curso.

Em termos operacionais, o curso é realizado durante um período de 15 meses, incluindo o cumprimento dos créditos e o desenvolvimento da monografia. A cada período de quatro ou cinco semanas, o aluno participa de duas disciplinas. A rotina das atividades é a seguinte: o aluno tem acesso a todo o material didático e precisa desenvolver as atividades didáticas em ambiente virtual de aprendizagem (AVA). A cada semana ele é avaliado e, entre a segunda e a terceira semana, realiza-se uma aula por vídeo ou web conferência. Neste momento, o docente no pólo de Curitiba apresenta uma aula panorâmica da disciplina e/ou organiza uma atividade para interagir com o discente com a finalidade de ao mesmo tempo sanar eventuais dúvidas e estimulá-lo ao estudo específico. Além disso, os alunos contam com um sistema de tutoria à distância e presencial. Semanalmente o tutor à distância marca chats e encontros no skype, mas os alunos podem se comunicar com eles a qualquer hora e dia por meio dos fóruns virtuais; enquanto os tutores presenciais ficam disponíveis diariamente nos pólos presenciais. A relação de tutores por alunos é um tutor a distância por turma e um tutor presencial para cada 25 alunos.

A infra-estrutura técnica e pedagógica disponibilizada aos alunos nos pólos presenciais é de responsabilidade da UTFPR, que conta com o apoio regulatório e financeiro do MEC/CAPES por intermédio da UAB/MEC, juntamente com o Poder Público local; além de laboratório de computação, biblioteca, para as atividades presenciais e como base de apoio para os estudos durante todo o curso.

No caso das atividades presenciais nesta modalidade de curso, elas incluem: assistir a aulas transmitidas por sistema de conferência; participar de atividades de interação síncrona (isto é, ao mesmo tempo) com os 
professores e tutores a distância, quando agendadas para serem executadas no pólo presencial; avaliações presenciais das disciplinas; dentre outras. No entanto, as atividades auto-instrucionais e demais atividades complementares da carga-horária, tais como, pesquisas, leituras, exercícios no caderno pedagógico da disciplina, atividades de interação assíncrona (isto é, não ao mesmo tempo) no AVA, como fóruns de discussão de temáticos das disciplinas; são as mais relevantes para este tipo de curso.

Desde a concepção do curso e, principalmente, na sua operacionalização, inúmeros desafios tem se apresentado ao gestor, docentes, discentes e técnico-administrativos da UTFPR.

Os desafios colocados ao gestor (coordenador de curso) referem-se à criação de mecanismos eficazes, que façam com que os professores realizem o planejamento minucioso e cumpram a sua execução para o desenvolvimento de suas atividades pedagógicas. Para o gestor, este é um desafio ao professor, pois ensinar à distância demanda, primeiramente, a relevância de se ter tudo planejado, pois o aluno à distância deve saber "as regras do jogo". A burocracia em termos de tornar público, por escrito, as "regras do jogo" é fundamental para a condução da disciplina e do curso. Diferentemente do dia a dia, em sala de aula, que muitas vezes o professor altera um cronograma em função do ritmo da turma; mas esta flexibilidade é descartada, neste tipo de ensino, que para ter qualidade deve ser minuciosamente planejado. Posteriormente, este planejamento deve ser cumprido, o que muitas vezes acaba não acontecendo, principalmente, no que concerne ao prazo de divulgar as médias de desempenho dos alunos, por exemplo.

No caso dos docentes do curso, eles apontam, primeiramente, ao crédito de qualidade que se deve dar a um curso nesta modalidade. Experiências passadas na história da educação no Brasil mostraram que os cursos, nesta modalidade, eram questionáveis por realmente qualificar os participantes; quiçá pela incapacidade dos discentes de serem autodidatas e desempenharam com afinco as atividades auto-instrucionais. No entanto, a experiência de dois anos tem modificado a imagem negativa dos cursos à distância por parte dos docentes na instituição. Outra questão crítica é orientar as monografias à distância. Os professores avaliam que a maioria dos alunos desconhece os métodos científicos e erram ao utilizar materiais de terceiros nas suas reflexões postadas em fóruns virtuais de debates, nas suas avaliações escritas e, principalmente, nas suas monografias. A comunicação virtual também tem seus ruídos, pois a escrita demanda maior maturidade para ser compreendida. No período das orientações de monografia, a compreensão dos discentes é divorciada da dos docentes, que durante o primeiro ano de experiência, contaram com o apoio de contatos telefônicos e conversas no Skype para sanar tais diferenças.

No caso dos alunos, os desafios não são menores. Aprender que o acesso por si só à informação não lhe concebe automaticamente conhecimento é um paradigma a ser ultrapassado. Por outro lado, ter capacidade para estudar sozinho e saber pesquisar fontes de informações 
complementares ao material didático, que é disponibilizado pelos professores; também é uma aprendizagem, pois o perfil do discente no nosso País é de dependente às instruções do professor tanto em termos de leituras a serem feitas como em termos do momento em que precisam estudar para serem avaliados. Muitos destes alunos percebem tais desafios quando realizam o curso, partindo de uma pré-concepção que são capazes de estudarem sozinhos. No entanto, amadurecer estudando sozinho requer disciplina e tempo; e esta condição a maioria dos alunos não tem, pois compartilham as responsabilidades de realizarem o curso com o trabalho profissional e os papéis familiares. Nestas condições, a presença e o contato com os professores são fundamentais para a sua aprendizagem, e o papel do tutor se torna relevante para este fator crítico.

$E$ os desafios aos técnico-administrativos é enfrentar mudanças na forma de se trabalhar. Para funcionários públicos burócratas, a zona de conforto de manter o status quo é preferível. Eles precisam conhecer as TIC's para estabelecer novas formas de relacionamento com professores e alunos. Estes funcionários incluem secretárias de curso e pessoal do apoio técnico, que acompanham as vídeo ou web aulas dos professores nos pólos presenciais envolvidos. Nos primeiros meses de funcionamento do curso, havia muitas falhas técnicas na transmissão da aula por web conferência, prejudicando os alunos de assistirem as aulas em dois pólos presenciais (Apiaí e Itapetininga). Ademais, a falta de comprometimento por parte de alguns funcionários prejudicava a realização de algumas atividades planejadas, como por exemplo, a gravação de todas as reuniões entre coordenação e professores; e a gravação das vídeo e/ou web aulas.

\section{Considerações Finais}

A UTFPR tal como demais instituições de ensino no Brasil dependem de um contexto sócio, econômico e político para definirem suas estratégias; bem como são afetadas pelos ditames regulatórios nas suas atividades, incluindo desde os processos de seleção à avaliação de desempenho, que no Brasil foram institucionalizados pelas reformas universitárias e pela Constituição Federal de 1988. Ademais, por ter natureza pública tem seus aspectos positivos e negativos quando inova em serviços, analisado neste trabalho de pesquisa, por meio da oferta de cursos de especialização e técnicos à distância.

A nossa questão central, neste trabalho, era analisar como uma universidade pública pode, dados os limites impostos pelo Estado, inovar na sua forma de gestão e na sua oferta de serviços e/ou produtos à sociedade? Como foi descrito, a UTFPR ao longo de sua história secular, ela se transformou de uma escola de aprendizes à uma universidade tecnológica. A sua expansão veio acompanhada de uma série de mudanças na sua estrutura administrativa e pedagógica; que foi possível pela autonomia universitária concedida às universidades públicas no que concerne aos aspectos didático-pedagógicos, financeiros e patrimonial. 
Hoje a instituição é administrada de forma descentralizada e participativa, contando com a atuação dos gestores entre os 12 Câmpus que congrega.

A experiência acumulada na docência conciliada com atividades de ensino, pesquisa e extensão orientadas ao mercado de trabalho, traço típico dos cursos técnicos e, que predominaram grande parte da história da UTFPR, fizeram com que a instituição fosse reconhecida pela sua comunidade regional como um lócus de desenvolvimento tecnológico. E, ao se transformar em uma universidade tecnológica, os desafios se tornaram elevados. Todas as mudanças historiadas mostram a sua capacidade de mudar, quer na sua estrutura organizacional, quer nos seus processos internos, quer em seus métodos pedagógicos, quer seja na oferta de serviços à comunidade regional. $E$, sobre estas inovações em produtoserviço, analisamos o caso específico da implantação e operacionalização do curso de especialização em GPM. Este projeto não apenas significou uma inovação em serviços prestados (curso na modalidade à distância, que trouxe uma nova maneira de se ministrar aulas, em um lócus virtual), mas trouxe consigo inovações em processos (diferentes formas de se relacionar com a comunidade acadêmica interna, por meio das tecnologias da informação e comunicação - TIC's), inovações organizacionais, ao criar uma estrutura técnica de suporte a tais atividades e a formalização de uma equipe de professores orientada para as atividades deste curso, que continuaram compartilhando suas demais responsabilidades com os cursos técnicos, de graduação e pós-graduação presenciais e de pessoal técnicoadministrativo para dar suporte administrativo; além do estabelecimento de parcerias com o privado, ao contratar profissionais autônomos para a prestação de serviços de tutoria; e inovação nas relações externas, pois o contato virtual, predominante, com os alunos diferenciou a forma de relacionamento com os seus "consumidores-alunos" e possibilitou oferecer ensino a regiões distantes fisicamente e carentes economicamente e socialmente.

No tocante aos desafios impostos aos docentes e discentes, destaca a postura dos professores frente aos cursos à distância. Apesar de muitos, no âmbito da instituição, ainda desacreditarem na capacidade de se oferecer estes tipos de cursos com qualidade; aqueles que se envolveram com o processo modificaram a sua percepção dada as suas experiências. Por outro lado, o corpo docente ainda carece de um repensar sobre as práticas pedagógicas orientadas ao ensino à distância para melhorar a qualidade dos cursos oferecidos, dado o perfil do discente, que por sua vez, apresenta sérias fragilidades para se adaptar à prática de ensino e aprendizagem por meio das tecnologias da informação e comunicação (TIC's). Por fim, o que parece ainda mais desafiador é mobilizar o pessoal técnico-administrativo, familiarizados com a burocracia pública, para as mudanças impostas à oferta dos cursos à distância. 


\section{Referências}

CÁCERES SALA, J. La gestión de la calidad en las Universidades Públicas Españolas: el Modelo Europeo de Gestión de la Calidad Total. $X$ Jornadas Luso-Espanholas de Gestão: Científica. Vilamoura, 2000.

CARNOY, M. Mondialisation et reforme de l'education. Paris: UNESCO, 1999.

CARNOY, M. Está a educação latino-americana preparando a força de trabalho para as economias do século XXI. Brasília: UNESCO, 2004.

GALLOUJ, F. Economia da inovação: um balance dos debates recentes. In: BERNARDES, R.; ANDREASSI, T. (Org.). Inovação em serviços intensivos em conhecimento. São Paulo: Saraiva, 2007.

KLINE, S.; ROSENBERG, N. Na overview of innovation. In: LANDAU, R.; ROSENBERG, N. (Eds.). The positive sum strategy: harnessing technology for economic growth. Washington D.C.: National Academy Press, 1986.

MEZA, Maria Lucia F.G. de. Empreendedorismo na Gestão Pública: inovação nas universidades diante da reforma do Estado no Brasil e das mudanças no mercado de trabalho. Curitiba, 2011.

TRINDADE, H. Reforma Universitária em Brasil: El desafio Del gobierno de Lula. Espacio Abierto Cuaderno Venezolano de Sociologia,v.16,n.1(ene/mar), 2007. pp.31-60.

UNIVERSIDADE TECNOLÓGICA FEDERAL DO PARANÁ. PLANO DE DESENVOLVIMENTO INSTITUCIONAL. UTFPR: Curitiba, 2007. Disponível em: < http://www.utfpr.edu.br/a-instituicao/documentos-institucionais/projetopolitico-pedagogico-institucional-1/projeto-politico-pedagogico-

institucional/view>. Acessado em: 20/02/2012.

UNIVERSIDADE TECNOLÓGICA FEDERAL DO PARANÁ. PLANO DE DESENVOLVIMENTO INSTITUCIONAL. UTFPR. Site institucional. Disponível em:< http://www.utfpr.edu.br/>. Acessado em:01/02/2012. 